\title{
Demographics and feeding ecology of whale sharks at Mafia Island, Tanzania
}

\author{
$\underline{\text { Fernando Cagua }}{ }^{1}, \mathrm{~J} \mathrm{Cochran}^{1}, \mathrm{C}$. Rohner $^{2}, \mathrm{M}$. Igulu $^{3}, \mathrm{~J} \mathrm{Rubens}^{4}$, S. Pierce $^{2,5}, \mathrm{M}$. Berumen $^{1,6}$ \\ edgar.cagua@kaust.edu.sa \\ ${ }^{1}$ Red Sea Research Center, King Abdullah University of Science and Technology, Saudi Arabia \\ ${ }^{2}$ Manta Ray and Whale Shark Research Centre, Marine Megafauna Foundation, Mozambique \\ ${ }^{3}$ Tanzania Fisheries Research Institute, Tanzania \\ ${ }^{4}$ World Wide Fund for Nature, Tanzania \\ ${ }^{5}$ Wild Me, Mozambique \\ ${ }^{6}$ Biology Department, Woods Hole Oceanographic Institution, United States of America
}

Background. The Western Indian Ocean is a globally important region for the whale shark Rhincodon typus, with well-studied coastal aggregation sites in southern Mozambique, Seychelles and Djibouti. Here we present an overview of a new study at Mafia Island, Tanzania.

Methods. We monitored whale shark abundances on 103 boat trips from October 2012-March 2013. We also used passive acoustic telemetry (VEMCO ${ }^{\circledR}$ V16 tags) and photographic identification to monitor the residency times and local movements of 29 tagged individuals. Shark sizes were estimated using laser photogrammetry.

Results. In total we observed 87 individual sharks with a mean of $5.1 \pm 5.2$ ( \pm SD) per trip and a peak in December of $8.2 \pm 6.3$. Total length ranged from 4.1 to $9.7 \mathrm{~m}$ and almost all sharks were immature. After boat-based visual observations dropped to zero in March 2013 (with the same ongoing sampling effort), the acoustic array still detected $75 \%$ of tagged sharks. Tagged individuals were detected by the acoustic array for $73 \pm 40$ days on average. They showed a strong site fidelity to a $15 \mathrm{~km}^{2}$ area in the inner part of the bay and then progressively moved offshore at the end of the season, matching a decrease in plankton abundance. Sharks were mostly observed feeding on dense patches of the pelagic shrimp Lucifer hanseni, often in association with planktivorous fishes. Photo IDs from 2007-09 and 2012-13 indicate that a large proportion of the juvenile individuals return to Mafia Island each spring-summer.

Conclusion. The size range and gender distribution of whale sharks at Mafia Island is similar to other coastal aggregations in the Indian Ocean, but the relatively high site fidelity and residency time stands in contrast.

Key words: whale shark aggregation, passive acoustic telemetry, planktivory, Lucifer hansoni, site fidelity 